\title{
Meu Ateliê: aplicativo de arteterapia para idosos depressivos
}

\author{
My Studio: Artetherapy application \\ for depressed elderly
}

\author{
Nathália Coelho Moreira ${ }^{[1]}$, Cecília Oliveira Boanova ${ }^{[2]}$
}

\begin{abstract}
Resumo: O artigo presente é um recorte do trabalho de conclusão de curso com o título "Meu ateliê: Aplicativo de arteterapia para idosos depressivos", defendido em agosto de 2021. Ele aborda o fenômeno do aumento da população idosa trazendo dados da OMS de 2019, que estima que no ano de 2032 o Brasil será considerado um país envelhecido. Frequentemente os idosos, tendo em vista o estereótipo da velhice vinculado a inutilidade, podem ser acometidos pela depressão, doença que se encontra em uma crescente. A partir dessas condições, surgem demandas inclusivas da sociedade, que necessitam da realização de pesquisas sobre este público. $O$ trabalho de conclusão propõe o desenvolvimento de um aplicativo digital de arteterapia com o objetivo de auxiliar os idosos no tratamento da depressão, visando minimizar os impactos da doença e contribuir com a qualidade de vida destas pessoas. Para sua construção, foi realizada uma pesquisa sobre as principais temáticas que circundam os sujeitos de pesquisa, tais quais: a depressão e como ela afeta o público idoso; a arteterapia; o uso de aplicativos móveis na terceira idade; a acessibilidade e a experiência do usuário caracterizada por princípios de design de interação e usabilidade. Como resultado, essa pesquisa reforça a importância de reconhecer o idoso como público alvo em projetos digitais e destaca a necessidade da inclusão da acessibilidade e experiência do usuário no desenvolvimento de interfaces digitais.
\end{abstract}

Palavras-chave: Design thinking; design de interfaces digitais; experiência do usuário; arteterapia; idoso; depressão.

Abstract: The present article is an excerpt from the course completion work entitled "My studio: Art therapy application for depressed elderly", defended in August 2021. It addresses the phenomenon of the increase in the elderly population, bringing data from the WHO from 2019, which it is estimated that in the year 2032 Brazil will be considered

[1] Bacharela em Design, IFSUL. ncoelhomoreira@gmail.com

[2] Doutora em Educação, UFPEL. ceciliaboanova@ifsul.edu.br 
an aging country. Elderly people, in view of the stereotype of old age linked to uselessness, can often be affected by depression, a disease that is on the rise. From these conditions, society's inclusive demands arise, which require research on this audience. This article proposes the development of a digital art therapy application with the objective of helping the elderly in the treatment of depression, aiming to minimize the impacts of the disease and contribute to the quality of life of these people. For its construction, a research was carried out on the main themes that surround the research subjects, such as: depression and how it affects the elderly population; art therapy; the use of mobile apps in old age; accessibility and user experience characterized by interaction and usability design principles. As a result, this research highlighted the importance of recognizing the elderly as the target audience of any digital project and highlights the inclusion of accessibility and user experience in the development of digital interfaces.

Keywords: Design thinking; digital interface design; user experience; art therapy; elderly; depression.

\section{INTRODUÇÃO}

A população idosa está aumentando significativamente em todo o mundo. Segundo a Organização Mundial de Saúde(OMS), um país torna-se envelhecido quando $14 \%$ da sua população total possui 65 anos ou mais. A estimativa é que em 2032 o Brasil se enquadre nesta situação, pois 32,5 milhões (14\%) dos mais de 226 milhões de brasileiros estarão presentes na faixa etária correspondente à terceira idade, ou seja, 65 anos ou mais (Sociedade Brasileira de Geriatria e Gerontologia, 2019).

Já a Pesquisa Nacional por Amostra de Domicílios Contínua (PNAD Contínua) Tecnologia da Informação e Comunicação (TIC) 2017, indica que a população idosa teve o maior crescimento proporcional de acesso à internet mesmo correspondendo ao menor grupo em relação às outras faixas etárias. $O$ aumento significativo foi de $6,4 \%$ quando considerando taxas de $24,7 \%$ (2016) para 31,1\% (2017). De acordo com a mesma pesquisa, os celulares foram os responsáveis por elevar e facilitar o acesso (IBGE).

No contexto atual, o aumento do acesso à internet também foi acelerado pela pandemia da COVID-19, de acordo com o presidente da Confederação Nacional de Dirigentes Lojistas (CNDL), que relata que muitos idosos passaram a utilizar a internet com o objetivo de manter contato com a família e fazer compras de forma segura, além de buscar informação e socializar nas redes sociais (CNDL, 2021). 
Com essa mudança populacional surgem desafios relacionados a políticas inclusivas e a características socioculturais e econômicas que proporcionem ao idoso uma vida com mais qualidade. O acesso à tecnologia e a inclusão digital são questões relevantes e que podem trazer benefícios para a saúde da terceira idade, podendo talvez contribuir para evitar ou retardar problemas relacionados ao envelhecer. Os aplicativos móveis são exemplos consideráveis no apoio ao idoso, pois oferecem recursos referentes ao autocuidado, também podem auxiliar médicos e familiares (AMORIM, 2018).

Juntamente com o fenômeno do envelhecimento populacional, é possível observar o aumento da depressão. A Pesquisa Nacional de Saúde (PNS) 2019, revelou que em 2019, $10,2 \%$ de pessoas com 18 anos ou mais receberam o diagnóstico de depressão sendo que em 2013 esse valor estava em 7,6\%. A mesma pesquisa mostra que o maior aumento situa-se na faixa etária de 60 a 64 anos (PNS, 2019).

De acordo com a OMS, a depressão é a doença que mais causa incapacidade às pessoas e na pior das hipóteses, quando não tratada, pode levar ao suicídio. Nos idosos, a depressão se torna recorrente em função de vários fatores relacionados ao envelhecer, como a autoestima reduzida, perda de estímulos cognitivos e sociabilidade, assim como o falecimento de pessoas próximas e a presença de outras doenças que aparecem com o avanço da idade (OPAS/OMS, 2018).

Os fatores do envelhecimento populacional em conexão ao aumento dos índices de depressão junto a população idosa ocasionam um cenário propício para pesquisas que visam contribuir com a qualidade de vida destas pessoas. Pensando no potencial criador dos designers para a solução de problemas centrados neste grupo específico - idosos depressivos - surgiu o questionamento sobre o que pode ocasionar um aumento na autonomia, na saúde e no bem-estar desses indivíduos.

Para responder tal questionamento, pensamos na potência dos aplicativos móveis e em sua eficiência no tratamento e na ajuda da saúde de um público tão particular. Como al- 
ternativa para alcançar uma solução possível, imaginamos a necessidade de uma abordagem empática voltada sensivelmente ao atendimento das necessidades dos idosos. A abordagem escolhida foi a do design thinking dos autores Ambrose e Harris (2011). Essa metodologia, que tem como premissa a empatia, contribui para solucionar questões referentes à usabilidade e a experiência do usuário, a fim de valorizar as especificidades do público-alvo.

Levando em consideração essas informações, criamos em forma de questão o seguinte problema: de que forma o desenvolvimento de um aplicativo móvel, baseado nos conceitos do design thinking, pode auxiliar no tratamento da depressão em idosos?

A fim de solucionar essa questão, buscamos apoio na literatura da arteterapia e elegemos a dissertação de mestrado, "Arteterapia e depressão: efeitos da arteterapia como terapia complementar no tratamento da depressão em idosos", de Eliana Cecília Ciasca (2017), como orientação para o projeto base de um aplicativo.

Utilizando os princípios de design de interação e usabilidade de Don Norman (2018) e Yvonne Rogers, Helen Sharp, e Jennifer Preece (2013), o aplicativo desenvolvido oferece ao idoso oficinas acessíveis de arteterapia, partindo da construção de uma experiência, podendo assim, auxiliá-los a trabaIhar suas emoções através de expressões artísticas.

\section{ARTETERAPIA E DEPRESSÃO EM IDOSOS}

A arteterapia, que une a psicoterapia e a arte, se apresenta como uma alternativa às pessoas que não se adaptam à psicoterapia verbal, podendo ser aplicada a todos os tipos de públicos. Ela ajuda as pessoas a lidarem com suas emoções e sentimentos através de expressões artísticas e processos criativos gerais que podem partir da pintura, da escultura, do desenho, da literatura, da dança, do audiovisual, da fotografia, da música e outros, onde o foco não é o resultado da técnica estética e sim a promoção do bem estar dos pacientes. 
Sua contribuição se encontra no desenvolvimento de uma visão crítica sobre as emoções, pensamentos e sentimentos, eleva o empoderamento e a autoconsciência, melhora a autoestima, diminui o estresse, além de promover novas habilidades (CIASCA, 2017).

Para os idosos, a arteterapia é um processo que os auxilia no enfrentamento de diversos problemas. Na depressão, a arteterapia permite que o idoso consiga expressar suas angústias, sentimentos de tristeza e também de perda, um acontecimento recorrente nessa etapa da vida, além de outros problemas relacionados a uma autoimagem negativa.

Segundo Ciasca (2017), criar espaços de acolhimento e afeto é essencial para o estímulo da expressão criativa, sendo importante na recuperação e na manutenção da saúde psíquica e emocional do público idoso, com isso, técnicas de relaxamento e imaginação dirigida se tornam aliados a essa prática.

A experiência da imaginação dirigida tem como objetivo criar imagens positivas, através do estímulo da audição, do olfato, da visão e do tato. Esse processo estimula um relaxamento muscular e proporciona uma mudança de percepção, trazendo efeitos positivos para as pessoas que sofrem de algum transtorno mental ou físico. A imaginação dirigida, é feita, geralmente, por terapeutas, psicólogos, enfermeiros ou outro profissional indicado (CIASCA, 2017).

Pensamentos negativos frequentes e a falta de atividade física, assim como poucos estímulos mentais, impedem que a pessoa depressiva saia de um ciclo vicioso cheio de reclamações e lamentações. A imaginação dirigida, nessas situações, pode auxiliar o paciente na quebra dessas atitudes sequenciais e promover uma possibilidade de saída, onde a partir da união entre o corpo e a mente o paciente acaba por ter atitudes mais positivas nas áreas psicológica, fisiológica e comportamental (CIASCA, 2017). 


\section{ACESSIBILIDADE DIGITAL E UX DESIGN}

De forma simplificada, entende-se por acessibilidade digital a "eliminação de barreiras na web", segundo o site do Governo Brasileiro ${ }^{[3]}$. De acordo com Costa (2019), a acessibilidade digital é uma prática realizada a partir de ações específicas presentes no desenvolvimento de produtos e conteúdos digitais, a fim de promover a garantia de acesso a todas as pessoas, incluindo principalmente as que possuem alguma deficiência (visual, motora, de fala e/ou cognitiva), de forma efetiva.

Dentre as deficiências acometidas pelas pessoas, a visual é a que mais se destaca no meio digital. A partir disso, algumas características acessíveis devem estar presentes no projeto, como contraste de cores, uso de elementos para grifar links, destacar botões, diferenciar elementos gráficos usando mais de uma alternativa (cor e textura, por exemplo), facilitar o preenchimento de formulários e o uso de ícones indicativos de alertas (COSTA, 2019).

Para que estas questões sejam atendidas, a fim de tornar o conteúdo web mais acessível, existem as Diretrizes de Acessibilidade para Conteúdo Web (WCAG) ${ }^{[4]}$, um documento que fornece padrões a serem seguidos, baseados por quatro princípios, que são: perceptível, operável, compreensível e robusto. Dentro de cada um existem critérios de sucesso, avaliados por um, dois ou três As - A, AA, ou AAA, de acordo com o atendimento às necessidades acessíveis existentes, 0 A atende as questões mais básicas e o AAA as mais complexas, proporcionando assim um alcance maior de pessoas.

O princípio perceptível, por exemplo, indica a facilidade de percepção do usuário sobre as informações e os componentes da interface. Ele é dividido em 4 diretrizes, sendo elas: alternativas em texto, mídias com base em tempo, adaptável e distinguível, sendo esta última pertencente ao critério de sucesso nível $A$, que fala sobre a utilização da cor não ser usada como o único meio visual de transmitir informações, indicar uma ação, pedir uma resposta ou distinguir um elemento visual.
[3] GOVERNO DO BRASIL. Disponível em: <https:// www.gov.br $>$ Acessado em:18/jun/2021.

[4] W3C. Disponível em: <https://www.w3c.br/> Acessado em: 18/jun/2021. 
Outro conteúdo específico que promove essa inclusão, são as Diretrizes de Acessibilidade do Material Design ${ }^{[5]}$, um sistema de design desenvolvido pela Google, com a proposta de auxiliar na criação de experiências digitais de alta qualidade. Nesse conteúdo há indicações de ícones, cores, tipografias, componentes, layouts e outros tópicos relacionados a projetar interfaces com acessibilidade, que partem de três princípios, sendo eles: ser claro (ajudar o usuário na navegação do aplicativo a partir do desenvolvimento de um layout limpo e objetivo); ser robusto (projetar pensando em alcançar todos os tipos de público) e ser específico (oferecer suporte a tecnologias assistivas ${ }^{[6]}$ compreendendo as possibilidades de acesso ao aplicativo).

Caminhando para além disso, a acessibilidade digital não é apenas sobre cooperar ou dar assistência, mas também beneficiar as pessoas que apresentam incapacidades momentâneas, como por exemplo, alguém que tenha realizado uma cirurgia em um dos olhos ou quebrado uma das mãos. Essa realidade aumenta o número de alcance dos sites e aplicativos, levando em consideração que as pessoas apresentam vontades, satisfações e frustrações diversas, tendo elas algum tipo de limitação ou não (LIMA, 2019).

Projetar com acessibilidade é assegurar uma boa experiência de usuário (UX) para qualquer indivíduo. Característica esta que deve ser garantida por profissionais que projetam interfaces digitais, visando a possibilidade de tornar o mundo um lugar de todos, principalmente para os idosos, que através da inclusão digital realizada pelas TDIC (tecnologias digitais de informação e comunicação), podem usufruir de bem estar, sentimentos de valor e utilidade, socialização, participação em grupos e comunidades virtuais, contribuindo para a melhora da saúde mental desse público (LIMA, 2019) (GUIMARÃES, 2019).

Experiência do usuário (UX), para Lowdermilk (2013), é toda a experiência que uma interface digital proporciona, tanto a nível de suas funcionalidades quanto aos seus atrativos. Logo, a experiência do usuário encontra-se no equilíbrio técnico da ferramenta, em complemento às capacidades de proporcionar estímulos agradáveis ao usuário.
[5] MATERIAL DESIGN ACCESSIBILITY. Disponível em: <https://material.io/ design/usability/accessibility. html\#understandingaccessibility > Acessado em: $17 /$ jul/2021.

[6] Recursos e serviços que contribuem para proporcionar ou ampliar habilidades funcionais de pessoas com deficiência e consequentemente promover vida independente e inclusão. (ASSISTIVA, 2021). 
A ISO 9241-210 define a experiência do usuário a partir de suas emoções e comportamentos relacionados à dinâmica de uso, ou seja, características presentes antes, durante e depois do processo interativo. Nesse desenvolvimento também se leva em conta as experiências anteriores que os usuários vivenciaram, a qual resultaram em algum tipo de pensamento ou ação.

Segundo Teixeira (2014), para que a experiência do usuário seja classificada como positiva é necessário que este realize as tarefas sem demora, sem frustração e sem o encontro de obstáculos durante a navegação. Também é necessário compreender que tal experiência é influenciada por fatores humanos e fatores externos, com a singularidade de cada pessoa e/ou grupos determinados.

Rogers, Sharp e Preece (2013) ressaltam que não se pode projetar uma experiência do usuário, mas sim criar características de design que transmitam uma determinada experiência do usuário. As autoras exemplificam estes quesitos, a partir de objetos casuais, como um telefone. Quando interagindo com a parte externa do objeto - a partir do toque, da observação e da interação - o usuário pode ter uma experiência satisfatória e agradável, ou sentir desconforto e insatisfação - dependendo da construção do projeto de design.

Em projetos interativos, especificamente, os aspectos de maior importância a serem considerados são: a usabilidade, a funcionalidade, a estética, o conteúdo, o look and fee ${ }^{[7]}$ e os apelos sensoriais e emocionais (ROGERS; SHARP; PREECE, 2013).

[7] Olhar e sentir em tradução livre.

A abordagem da experiência do usuário é voltada diretamente para as necessidades das pessoas, valorizando a empatia nos projetos de design. Os idosos caracterizam-se por ser um grupo heterogêneo, o que dá abertura para uma pesquisa aprofundada a fim de promover a desconstrução de estereótipos sociais voltados para este grupo. Essas abordagens contribuem para a melhoria da compreensão de suas necessidades, estimulam a criatividade e consequentemente os resultados são mais precisos e satisfatórios. 


\section{DESIGN DE INTERAÇÃO E USABILIDADE}

Por que toleramos as frustrações de objetos do cotidiano, com coisas que não conseguimos descobrir como usar, com aquelas elegantes embalagens embrulhadas em plástico que parecem impossíveis de abrir, com portas que prendem pessoas, com máquinas de lavar e secadores que se tornaram confusos demais para serem usados, com sistemas de áudio-estéreo-televisão gravadores-videocassete que nos anúncios de publicidade afirmam fazer tudo, mas que tornam quase impossível fazer qualquer coisa? (NORMAN, 2018, p. 23).

De acordo com Norman (2018), as frustrações geradas por objetos do cotidiano, são consequência de um design mal projetado e que infelizmente se encontram em maioria no mercado. São objetos complexos, que muitas vezes induzem o usuário ao erro ou contém informações falsas. Essas características se encontram principalmente no campo digital, onde o autor indica um déficit em projetos que atendam as expectativas dos usuários.

A partir destas colocações, é possível identificar a urgência em desenvolver produtos interativos que sejam agradáveis, eficazes e de fácil manuseio e entendimento para os usuários. Em outras palavras, garantir uma experiência satisfatória às pessoas através da usabilidade é o objetivo que move a área de design de interação (ROGERS, SHARP E PRECCE, 2013).

Em complemento, com o objetivo de mudar o campo do design digital, Norman (2018), descreveu seis princípios essenciais que norteiam um bom projeto de design de interação. São eles: visibilidade, feedback, restrições, affordance, mapeamento e consistência.

Rogers, Sharp e Preece (2013), exploram a relação entre design de interação e usabilidade. O design de interação parte da estrutura visual e a usabilidade garante que as características do design estejam atendendo as necessidades do usuário. Ambos funcionam juntos, com o objetivo de projetar boas experiências. 
Assim como Don Norman sugeriu fundamentos do design de interação, Jakob Nielsen propôs os dez princípios de usabilidade, que se relacionam com alguns fundamentos citados anteriormente, sendo eles: visibilidade do status do sistema (feedback), compatibilidade do sistema com o mundo real (linguagem utilizada), controle do sistema e liberdade (saídas de emergência), consistência e padrões (não fazer o usuário pensar), ajudar os usuários a reconhecer, diagnosticar e se recuperar de erros (estrutura simplificada), prevenção de erros (onde possível, evitar erros), reconhecimento em vez de memorização (elementos visíveis), flexibilidade e eficiência de uso (usuário inexperiente e usuário experiente), estética e design minimalista (evitar informações irrelevantes), ajuda e documentação (informações e passos facilmente encontrados) (ROGERS, SHARP E PRECCE, 2013).

Para garantir uma usabilidade eficaz, é necessário realizar testes de usabilidade a fim de entender como o usuário interage com o projeto. Eles servem para avaliar o desempenho dos usuários ao realizar determinadas funções, com o intuito de esclarecer o quanto o projeto é usável, levando em consideração a facilidade de uso e a capacidade de aprendizado. Para a realização dos testes, é necessário utilizar uma série de técnicas, que incluem observações, questionários e entrevistas. Nesse processo podem ser analisados o tempo que o usuário levou para concluir determinados comandos, o número de erros cometidos e o caminho que cada usuário percorreu dentro do projeto (ROGERS, SHARP E PRECCE, 2013).

Separados em duas categorias, os testes podem se apresentar de maneira formativa ou somativa. Os testes formativos servem para descobrir possíveis problemas na intenção de melhorar o produto e os somativos medem a performance e comparam o produto com outros concorrentes. Geralmente o formativo ocorre durante o desenvolvimento e o somativo quando o produto está concluído e aplicado (VOLPATO, 2019). 


\section{METODOLOGIA}

Este trabalho foi dividido em duas etapas, sendo a primeira referente à pesquisa e a segunda ao projeto. A estrutura metodológica adotada foi baseada em solucionar de forma eficaz o problema desta pesquisa atendendo aos objetivos que a seguem.

Para admitir seu desenvolvimento, levando em conta a realização desses dois momentos, optamos pela abordagem do design thinking, uma metodologia centrada no usuário que busca construir ideias de design criativas que possam apresentar e comunicar as informações para o seu público de maneira mais eficiente.

Na visão dos autores Ambrose e Harris (2011), o design thinking se caracteriza por contemplar sete etapas, sendo elas: definir, pesquisar, gerar ideias, testar protótipos, selecionar, implementar e aprender. Por sua flexibilidade, exige a retomada de etapas no decorrer do projeto para possíveis reformulações, como mostra a figura 1.

Figura 1 - Etapas do design thinking. Fonte: AMBROSE; HARRIS, 2011

A construção projetual foi dada pelo seguimento das etapas do design thinking. Geração de ideias é a terceira etapa, conforme a explicação anterior. É nesse momento que surgiram possíveis soluções. Para chegar até este momento, as etapas de definir e pesquisar foram concluídas, onde compreendemos que a definição partiu do encontro com o problema da pesquisa e pesquisar deu-se pela estruturação do referencial teórico. 
Para o desenvolvimento de geração de ideias foi necessário retomar a etapa de pesquisa, como prevê a metodologia do design thinking, a retomada de processos para a eficiência do projeto. A pesquisa foi realizada a partir de artigos científicos, onde utilizamos como base uma dissertação de mestrado realizada na área de medicina, que teve como resultado apresentado a melhora significativa da depressão em idosos. O olhar profissional perante a formulação do aplicativo é relevante, dá credibilidade a proposta, que é auxiliar os idosos, além de embasar as escolhas construtivas do projeto.

O título referido é "Arteterapia e depressão: efeitos da arteterapia como terapia complementar no tratamento da depressão em idosos", escrita em (2017) por Eliana Cecília Ciasca. O resultado do estudo partiu da realização de oficinas de arteterapia, onde os idosos participaram de 20 sessões em grupo ocorridas semanalmente. Elas começavam com práticas de imaginação dirigida e relaxamento com o intuito de estimular a criatividade e deixá-los mais receptivos às emoções, logo depois eles recebiam materiais para criar a partir do que sentiam no momento finalizando com o compartilhamento de suas criações.

As práticas que montaram as oficinas, nortearam o desenvolvimento do aplicativo deste projeto que tem como objetivo tornar a arteterapia mais acessível, como mostra os wireframes da figura 2. Os aplicativos, quando bem estruturados, segundo Amorim (2018) proporcionam bem-estar e autonomia aos idosos, podendo ser uma alternativa para os que sofrem de depressão e que muitas vezes não têm acesso a outros tipos de tratamentos. 


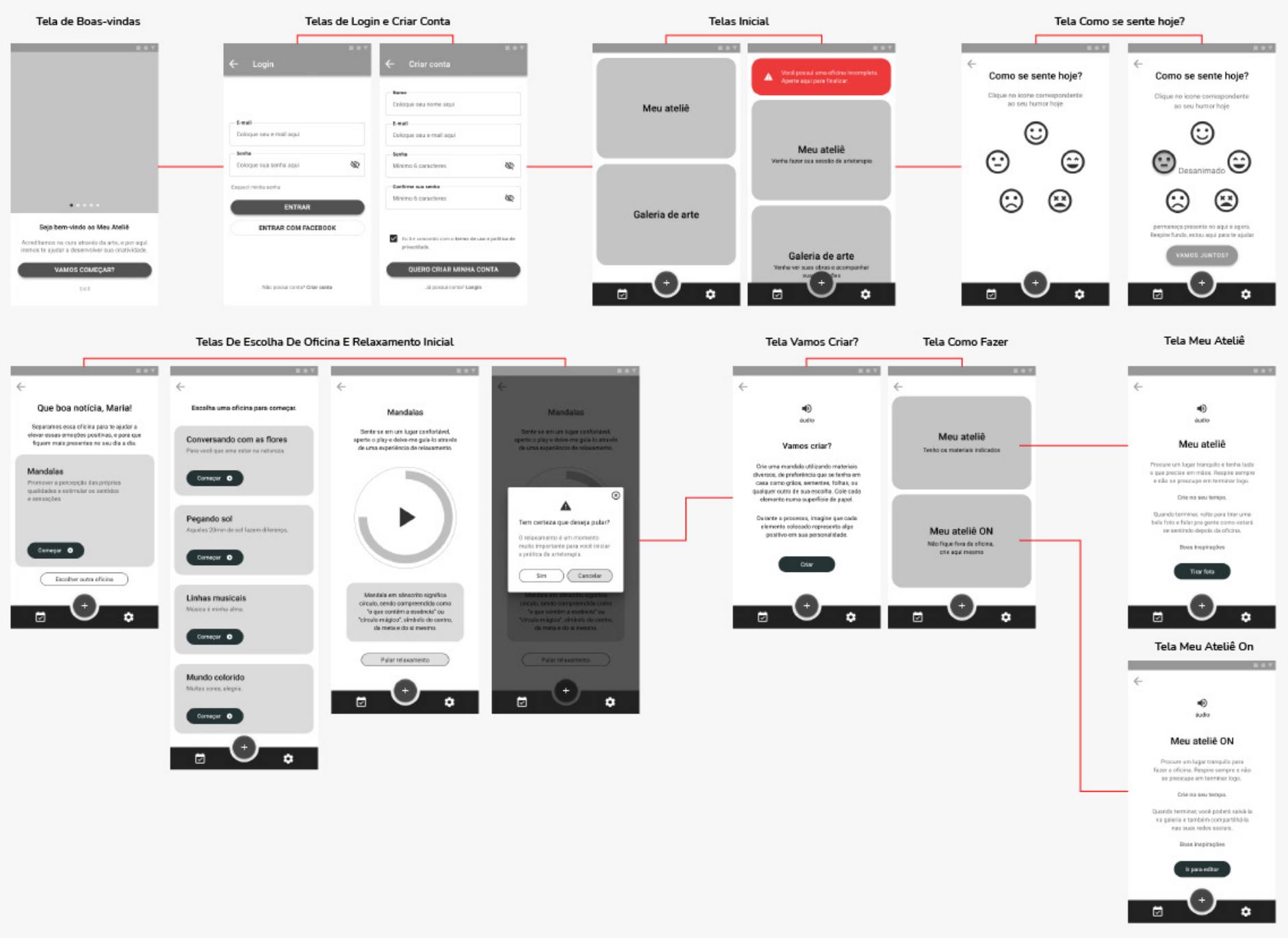

Figura 2 - Wireframes. Fonte: Acervo da autora (2021).

\section{PROTÓTIPO}

A parte de prototipagem é onde o projeto ganha forma, concretizando visualmente todo o processo de seu desenvolvimento. Nesta etapa definimos o nome do projeto, assim como o logo do aplicativo e a direção de arte das telas, terminando na construção do protótipo navegável do aplicativo Meu Ateliê.

Para o nome do aplicativo usamos como referência as características da linguagem presente na prática da arteterapia. Meu Ateliê conversa com a ideia espacial de expressão e privacidade e traz questões mais profundas ligadas à autonomia do idoso. O ateliê se relaciona com o campo da arte sendo mais positivo a outras possibilidades, que trariam a idade ou a própria doença como foco. 
O logotipo desenvolvido para o projeto se caracteriza por ser tipográfico, formado por uma família modificada, que significa que um ou mais caracteres foram redesenhados. $\mathrm{O}$ objetivo foi reforçar o próprio nome, levando em consideração a legibilidade, que é uma questão fundamental na criação de logotipos (PEÓN, 2001).

Usando como referência outros aplicativos relacionados com a temática, como o aplicativo Headspace e o Zen, ambos voltados para a prática de meditação e relaxamento, observamos o uso de logotipos tipográficos dispostos de maneira horizontal. A simplicidade é um ponto relevante e conversa com trabalhos voltados para a área digital, conforme mostra a figura 3.

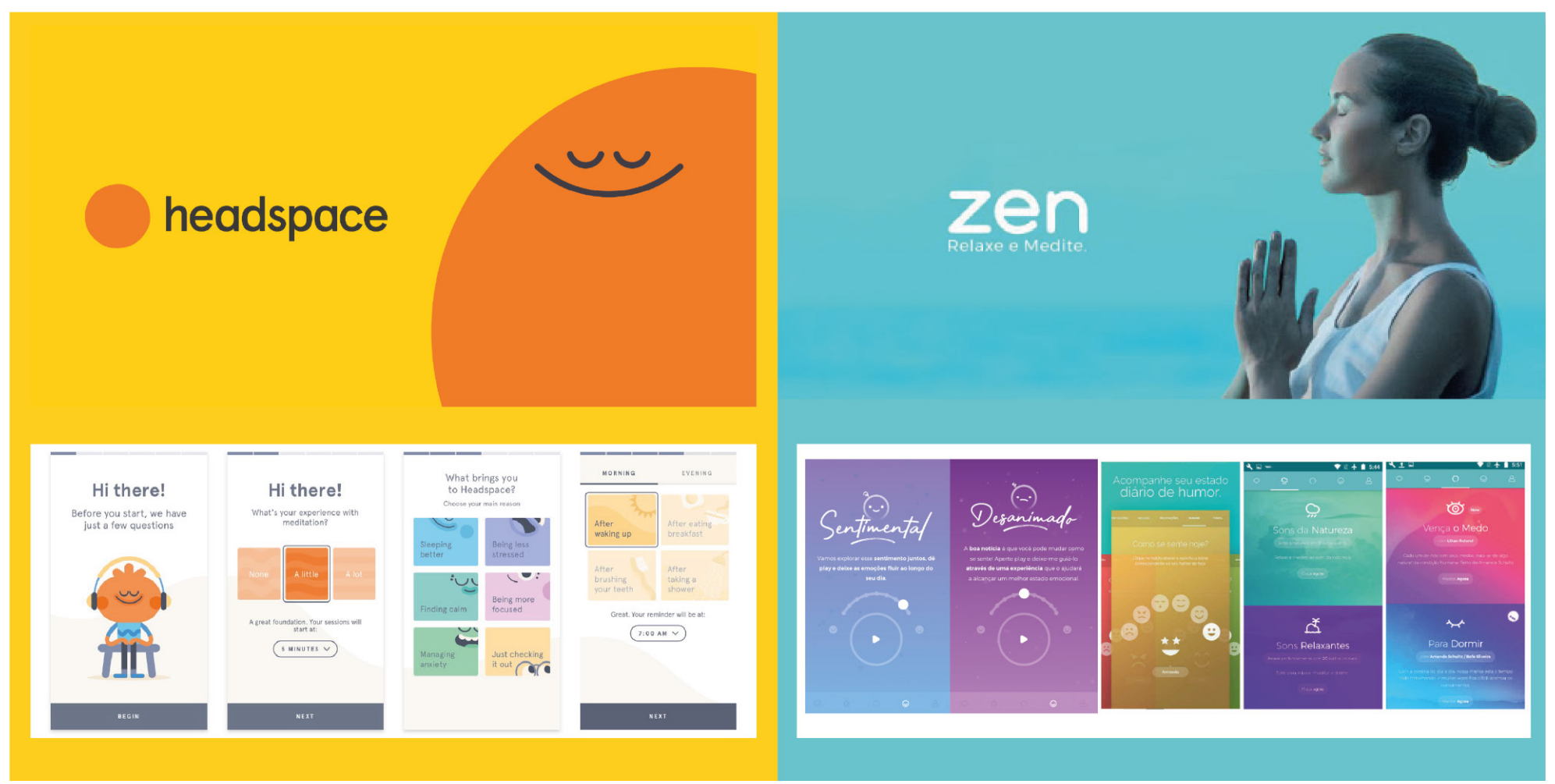

Figura 3 - Aplicativos de referência. Fonte: Compilação da autora (2021) Disponível em: <https://bit.ly/3rivvHA>; <https://bit.ly/36PgXWG>; <https://bit.ly/3kBmOYo>; <https://bitlly/3BiF8eg>; <https://bit.ly/2UXPiQK> Acessado em: 19/jul/2021 
Para a estruturação do logo realizamos uma pesquisa direcionada para encontrar elementos que conversassem com a arte e com o propósito do aplicativo: auxiliar pessoas. Partindo dessa premissa, chegamos a imagem do cavalete, objeto presente nos ateliês de arte que serve para apoiar os quadros, um elemento que representa suporte.

Em seguida, analisando o nome e possíveis pontos de maior influência, optamos por salientar a letra " $A$ ", da palavra ateliê. A letra faz referência a estruturação de um cavalete aberto, como mostra na figura 4, trazendo características de começo, devido a sua posição inicial no alfabeto, de direção e motivação, a partir do encontro das arestas que apontam para cima. Começo, direção e motivação foram palavras-chave na concepção do projeto, que tem como público alvo idosos com depressão.

\section{meuAteliê}

A tipografia escolhida foi a Nunito, tanto para a construção do logo quanto para os textos do aplicativo, com o objetivo de estabelecer simplicidade e objetividade visual devido a sua estrutura não serifada, além de trazer características de afeto, aconchego e conforto, suscitadas a partir de seus cantos arredondados. Ela não possui variação de espessura, dando estabilidade para a marca.

Tipografias não serifadas são mais indicadas e acessíveis para o uso em dispositivos digitais, pois facilitam a diferenciação entre seus caracteres, diferente das tipografias com serifa, que por possuírem extremidades com alongamentos, podem dificultar a leitura (CTA, 2020).
Figura 4 - Logo desenvolvido para o aplicativo Meu Ateliê. Fonte: Acervo da autora (2021). 
O projeto realizado teve como objetivo a acessibilidade em sua totalidade, o que influenciou nessa escolha. Nunito não apresenta caracteres ambíguos, como por exemplo a vogal "I" maiúscula se diferenciar da consoante "I" minúscula, assim como o número " 0 " se diferenciar da letra "o", como mostra a figura 5, garantindo assim uma boa legibilidade para o aplicativo (CTA, 2020).

Figura 5 - Exemplo dos caracteres não ambíguos da fonte Nunito. Fonte: Acervo da autora (2021)

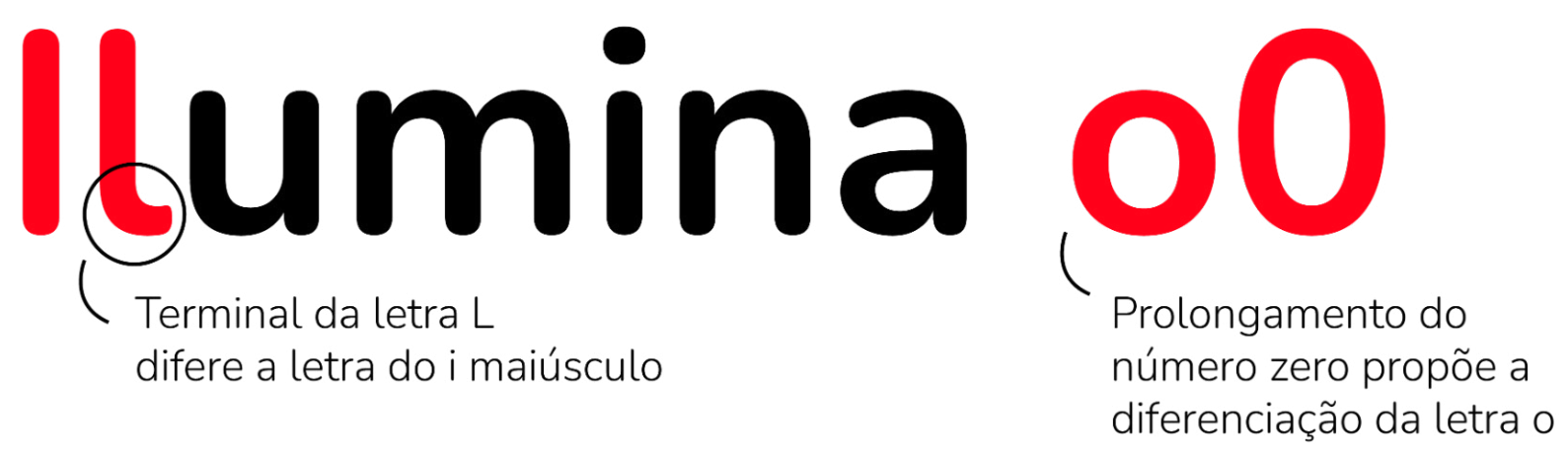

As cores definidas para o projeto foram o amarelo e 0 violeta, devido às suas características embasadas pela cromoterapia, uma terapia alternativa que trabalha as cores em tratamentos de doenças. O violeta serve como um calmante e é muito utilizado em meditações, melhora o sono e alivia a dor e o amarelo ajuda a melhorar estados de depressão, apatia e desânimo. (AZEEMI, 2007)

A partir da acessibilidade, o Material Design disponibiliza referências à utilização das cores em interfaces digitais, onde indicam o contraste do texto em relação às cores escoIhidas, conforme a figura 6. 

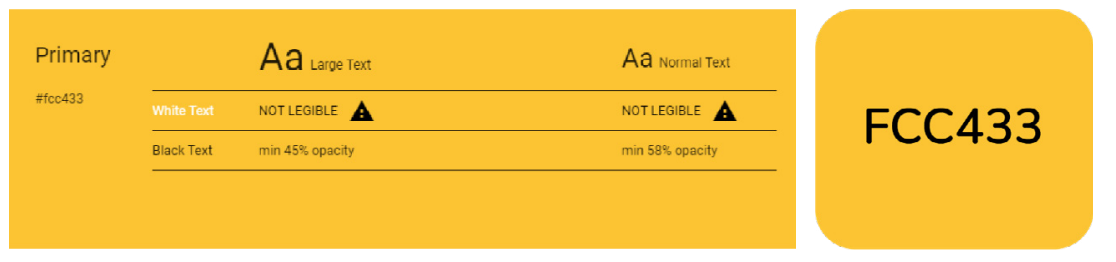

Figura 6 - Acessibilidade das cores disponibilizadas pelo Material Design. Fonte: Acervo da autora (2021).
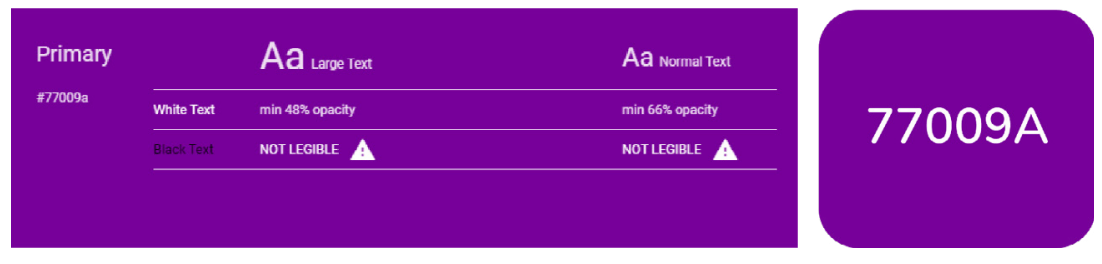

Esse material indica que o uso da letra branca sobre a cor amarela não é legível, tanto em textos com letras maiores, quanto em textos com letras normais e sugere que a opacidade mínima do texto preto (adequado) seja de no mínimo 45\% para textos grandes e $58 \%$ para textos normais. Já a acessibilidade da cor violeta, indica que a cor preta não é legível e sugere que as opacidades mínimas na cor branca sejam de $48 \%$ para textos grandes e $66 \%$ para textos comuns.

De acordo com Peón (2001), as cores de uma marca devem proporcionar pregnância, estando presentes em todo o projeto, incluindo as aplicações necessárias, garantindo uma identidade visual eficiente. Nesse caso, o logo e a identidade de todo o aplicativo foram baseados nessas duas cores, como é possível visualizar na figura 7, nas variações aplicativas do logo.

\section{meu/teliê meuAteliê}

Figura 7 - Uso das cores no logo desenvolvido para o aplicativo Meu Ateliê. Fonte: Acervo da autora (2021).

\section{meuAteliê meuAteliê}


Com essas definições, o visual do aplicativo foi desenvolvido procurando atender todas as questões de acessibilidade pesquisadas, como: cor, tipografia, contraste, estrutura, elementos visuais, assim como contemplar questões de usabilidade e design de interação favorecendo a relação entre os idosos e a interface do dispositivo móvel, como mostram as figuras 8 e 9.

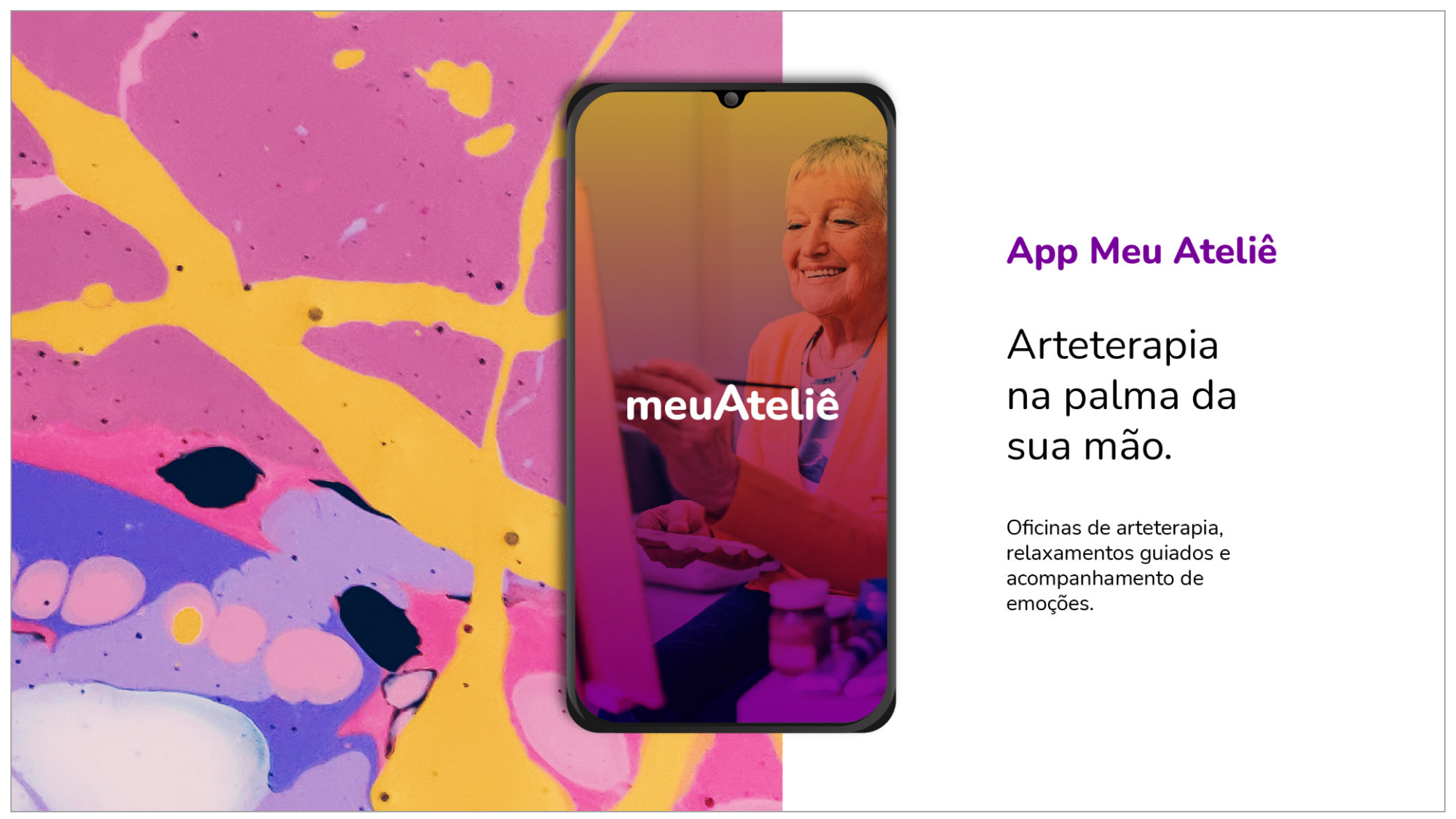

Figura 9 - Telas finais do aplicativo Meu Ateliê. Fonte: Acervo da autora (2021). 


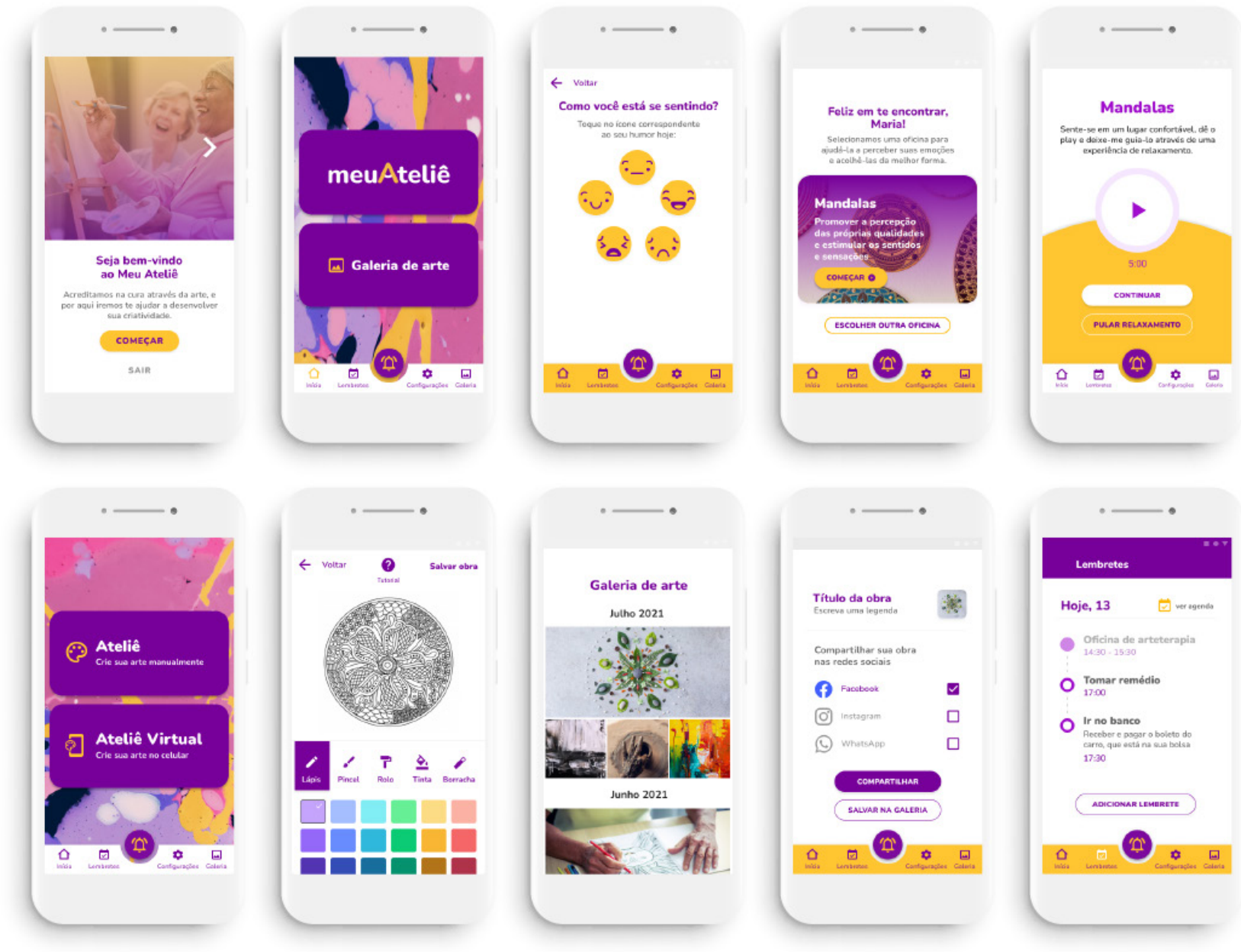

Figura 8 - App Meu Ateliê. Fonte: Acervo da autora (2021).

\section{CONCLUSÃO}

Este projeto mostrou a potencialidade que o design tem em proporcionar qualidade de vida às pessoas, principalmente as que possuem algum tipo de limitação, com foco na área digital. Através da utilização de uma abordagem empática, o projeto proporcionou o entendimento sobre a importância de projetar a partir do conceito de experiência do usuário, juntamente com questões de acessibilidade, como forma de atender as necessidades do público a que se destina. Além disso, salientamos a característica interdisciplinar do design, que explora diversas ferramentas e conteúdos com o objetivo de solucionar obstáculos cotidianos. 
Nesse sentido, a metodologia do design thinking, por ser centrada no usuário e ter como premissa a empatia, foi fundamental para a construção, onde através de suas etapas flexíveis, foi possível desenhar os caminhos necessários para alcançar a eficiência proposta.

Para além das funcionalidades, as pesquisas feitas sobre a depressão do idoso levantaram pontos que foram essenciais na construção projetual. Pontos estes que se relacionam com o afeto e com a autoimagem negativa do próprio público, onde foram explorados através do uso de textos motivadores e imagens positivas de idosos, mostrando que eles são capazes de realizar todas as oficinas.

A escolha pelo desenvolvimento de um aplicativo, também se deu através de pesquisas que mostram que o público idoso está interagindo cada vez mais com o meio digital, principalmente nesse momento pandêmico, revelando o aumento da adesão de dispositivos digitais em $97 \%$ no ano de 2021.

Tendo em vista essa realidade, é preciso reconhecer o idoso como público alvo de qualquer aplicativo ou outro projeto digital, tornando indispensável a inclusão da acessibilidade e experiência do usuário, a fim de tornar possível a utilização satisfatória desses dispositivos. Da mesma forma, compreendemos que projetar com acessibilidade é possibilitar que outras pessoas, não só os idosos, possam usufruir do produto. Sendo assim, o aplicativo Meu Ateliê pode ser utilizado por outros grupos de pessoas, que queiram ou necessitem de terapia alternativa.

Neste processo também destacamos a relevância das Diretrizes de Acessibilidade do Material Design, conteúdo este que nos auxiliou no desenvolvimento projetual. A partir dele, compreendemos que desenvolver interfaces acessíveis é possível, revelando a responsabilidade social que todo designer ou profissional que desenvolve conteúdos digitais deve seguir.

Com isso, concluímos que há muitas ferramentas que promovem a qualidade na vida das pessoas, tanto as que possuem algum tipo de limitação, quanto as que não pos- 
suem. De fato, é preciso concordar com Don Norman quando diz "nós não temos obrigação de viver a experiência de nos sentirmos confusos nem de sofrer por erros não descobertos. O design correto pode afetar positivamente nossa qualidade de vida" (NORMAN, 2018, p. 293).

\section{REFERÊNCIAS BIBLIOGRÁFICAS}

AMBROSE, Gavin; HARRIS, Paul. Design Thinking.

Porto Alegre: Bookman Editora, 2011.

AMORIM, Diane Nogueira Paranhos et al. Aplicativos móveis para a saúde e o cuidado de idosos. Revista

Eletrônica de Comunicação, Informação e Inovação em Saúde, v. 12, n. 1, 2018.

\section{AZEEMI, S. T. Y. A Quantitative Study On}

Chromotherapy. (2007). Disponível em <https:// bit.ly/3IZkZxz> Acesso em 28 de junho de 2021.

Assistiva Tecnologia e Educação, 2021. Disponível em: <https://www.assistiva.com.br/tassistiva. html> Acesso em 17 de julho de 2021.

BROWN, Tim. Design Thinking: Uma metodologia poderosa para decretar o fim das velhas ideias. Rio de Janeiro: Elsevier, 2010.

CIASCA, Eliana Cecília. Arteterapia e depressão: efeitos da arteterapia como terapia complementar no tratamento da depressão em idosos. 2017.

Dissertação de mestrado. Universidade de São Paulo. COSTA, Hugo. Acessibilidade digital: Cores, componentes e ferramentas. Medium, 2019. Disponível em <https:// bit.ly/3p7mr97> Acesso em 04 de abril de 2020.

Depressão. OPAS, 2018. Disponível em: <https://www.paho. org/pt/topicos/depressao> Acesso em 12 de agosto de 2019. 
DIS, ISO. 9241-210. Ergonomics of human system interaction-Part 210: Human-centred design for interactive systems. International Standardization Organization (ISO). Switzerland, 2009.

Governo digital. gov.br, 2019 Disponível em: <https:// bit.ly/3shINGZ> Acesso em 04 de abril de 2020.

GUIMARÃES, Felipe T. Inclusão Digital na Terceira Idade: Considerações sobre a Experiência com a Informática. Congresso Brasileiro de Informática na Educação, VIII., 2019, Paraná.

LOWDERMILK, Travis. Design centrado

no usuário. Novatec Editora, 2013.

LIMA, Lucas Figueiredo. Acessibilidade digital não é um bicho de 7 cabeças. Use Mobile, 2019.Disponível em: <https://bit.ly/3IUqwp8> Acesso em 04 de abril de 2020.

NORMAN, Donald A. 0 design do dia a dia. Editora Rocco, 2018.

Número de idosos que acessam a internet cresce de $68 \%$ para $97 \%$, aponta pesquisa CNDL/SPC Brasil. CNDL Brasil, 2021. Disponível em: <https:// bit.ly/3p92f6R> Acesso em 08 de julho de 2021.

OMS divulga metas para 2019; desafios impactam a vida de idosos. SBGG, 2019. Disponível em: <https:// bit.ly/3e7CoWS> Acesso em: 30 de outubro de 2019.

PEÓN, Maria Luísa. Sistemas de

identidade visual. $2 A B, 2001$.

Pesquisa Nacional de Saúde 2019, Percepção do estado de saúde, estilos de vida, doenças crônicas e saúde bucal. PNS, 2019. Disponível em: <https:// bit.ly/3e79uWQ> Acesso em 08 de julho de 2021 
ROGERS, Yvonne; SHARP, Helen; PREECE, Jennifer. Design

de Interação. Porto Alegre: Bookman Editora, 2013.

TEIXEIRA, Fabrício. Introdução e boas práticas

em UX Design. Editora Casa do Código, 2014.

Tipos de fonte e acessibilidade digital. CTA, 2019. Disponível em: <https://bit.ly/30DMdIL> Acesso em: 19 de junho de 2021.

VOLPATO, Elisa. Pesquisa: métricas em teste de usabilidade. Testr, 2019. Disponível em: <https:// bit.ly/3qfHtSG> Acesso em: 22 de abril de 2021. 